\title{
GPR survey to confirm the location of ancient structures under the Valencian Cathedral (Spain)
}

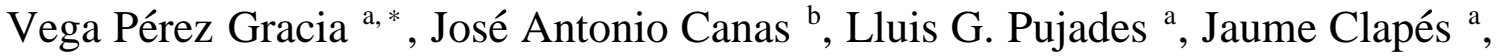 \\ Oriol Caselles a ${ }^{a}$ Francesc García ${ }^{c}$, Raul Osorio ${ }^{\mathrm{d}}$ \\ ${ }^{a}$ Department of Geotechnical Engineering and Geosciences, Technical University of Catalonia, C / Gran Capitán s / n, \\ 08034 Barcelona, Spain \\ ${ }^{\mathrm{b}}$ Instituto Geográfico Nacional, C / General Ibáñez Ibero, $n$ 3, Madrid, Spain \\ ${ }^{c}$ Departamento de Cartografía, Geodesia Geofísica, Universidad Politécnica de Valencia, Valencia, Spain \\ ${ }^{\mathrm{d}}$ Departamento de Enginyeria Minera i Recursos Naturals, Universidad Politécnica de Catalunya, Spain
}

Received 23 September 1998; received in revised form 19 February 1999; accepted 22 July 1999

\begin{abstract}
This paper describes the ground-penetrating radar (GPR) survey performed inside the Cathedral of Valencia, Spain. It is part of historical studies performed in the Cathedral in order to add information to old maps and documents in the Cathedral Archives and also to analyze the extent and importance of potentially destructive moisture areas that were appearing on the floor. The construction of the Cathedral of Valencia occurred in three stages, all of which are well-documented in the Cathedral Archives with detailed drawings, maps, and charts. The radar data were successful in locating crypts, ossuaries, sepulchers, and graves, and the location of ancient walls that existed before the final Cathedral expansion. Three cultural layers corresponding to the three periods of construction were also identified corresponding to the Roman, Arabian and Middle Age Epochs. Measurements of relative sub-floor moisture were obtained by comparing dielectric permittivity changes and radar velocity differences between materials in humid and non-humid areas. (C) 2000 Elsevier Science B.V. All rights reserved.
\end{abstract}

Keywords: Ground-penetrating radar (GPR); Archaeology; Restoration; Humidity damage; Historical heritage; Archaeological prospecting

\section{Introduction}

The study of archaeological sites with ground-penetrating radar (GPR) is widely documented (Conyers and Goodman, 1997; Conyers

\footnotetext{
* Corresponding author. Tel.: +34-93-401-72-57; fax: +34-93-401-72-51; e-mail: dperezg@etseccpb.upc.es
}

et al., 1996; Goodman, 1994; Lorenzo Cimadevila, 1994), and numerical simulations of buried materials have been applied to these types of studies (Goodman, 1994; Carcione, 1996). The Cathedral of Valencia is one of the most important historical monuments in Spain. Its construction began in 1262, and finished in 1530. Built over the ancient remains of an Arabian mosque 
and Roman ruins its construction was performed in three main stages: (I) an ancient Romanesque church was built between 1262 and 1330; (II) some significant modifications and the construction of a tower were performed between 1330 and 1430; and (III) the church was expanded and some additional changes were completed between 1430 and 1530 (Gavara, 1997).

Materials surrounding the cathedral are mainly alluvial deposits (gravel, sands and clay). Some test holes near the cathedral uncovered alluvial materials up to $20 \mathrm{~m}$ deep. The ground water is found at depths ranging from 7 to $9 \mathrm{~m}$. The area of interest is no deeper than $3 \mathrm{~m}$, well within the range of GPR surveying techniques. GPR surveys were performed within the cathedral along profiles within the main and lateral naves of the cathedral, the ambulatory, the transept and the altar. A map of the GPR profiles, together with the floor plan of the church, are shown in Fig. 1.

A $500-\mathrm{MHz}$ center frequency antenna was used in all profiles. It had maximum energy penetration to about $3 \mathrm{~m}$. Antennas with lower center frequencies did not have enough resolu- tion to locate the small target features such as graves and ossuaries.

\section{Crypts, ossuaries and graves}

The main structures detected using the GPR survey were crypts. The old maps in the archives delineate three important crypts. The largest crypt, "Canónigos" Crypt, contains the most recent burials and is located below the main nave, just in front of the main altar. The first documentation on this crypt is a parchment plan dated in 1754. Radar profiles obtained along the main nave of the church, over this crypt area, clearly show a significant reflection signature created by internments. The reflection anomalies are caused by a sharp radar velocity contrast between the buried void space and the adjacent media (lines P1 and P5 in Fig. 2). The dielectric permittivity of the matrix material surrounding the burials is about 9 . It was obtained by measuring GPR travel times to known target objects. Other authors report similar dielectric permittivity values for similar materials

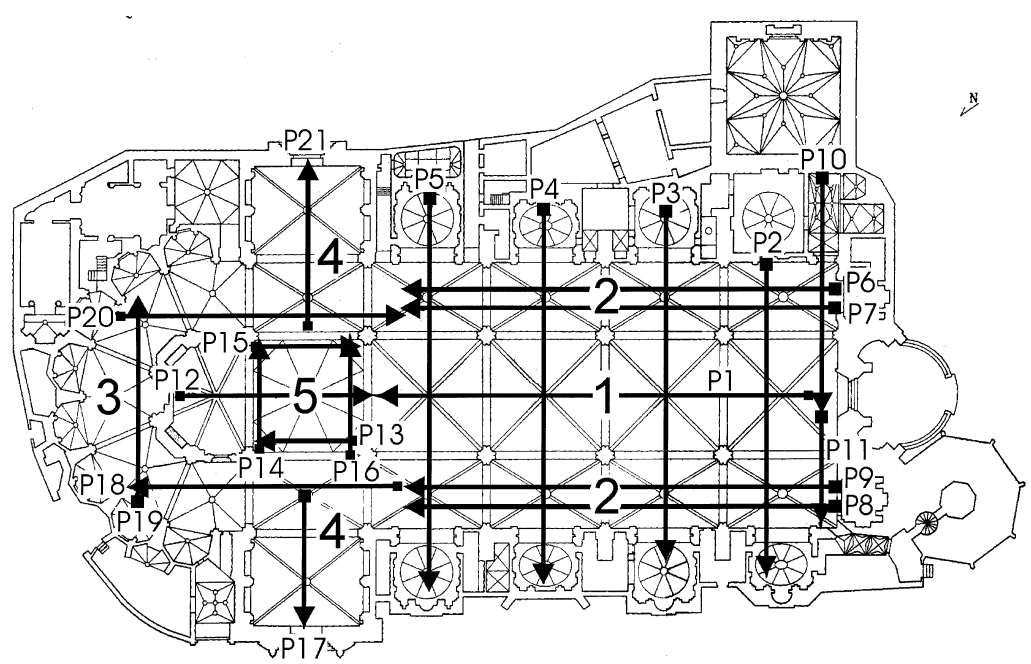

Fig. 1. Plan of the Cathedral and location of GPR profiles. The different areas of the Cathedral are indicated: (1) main nave, (2) lateral naves, (3) ambulatory, (4) transept and (5) altar. 
a)

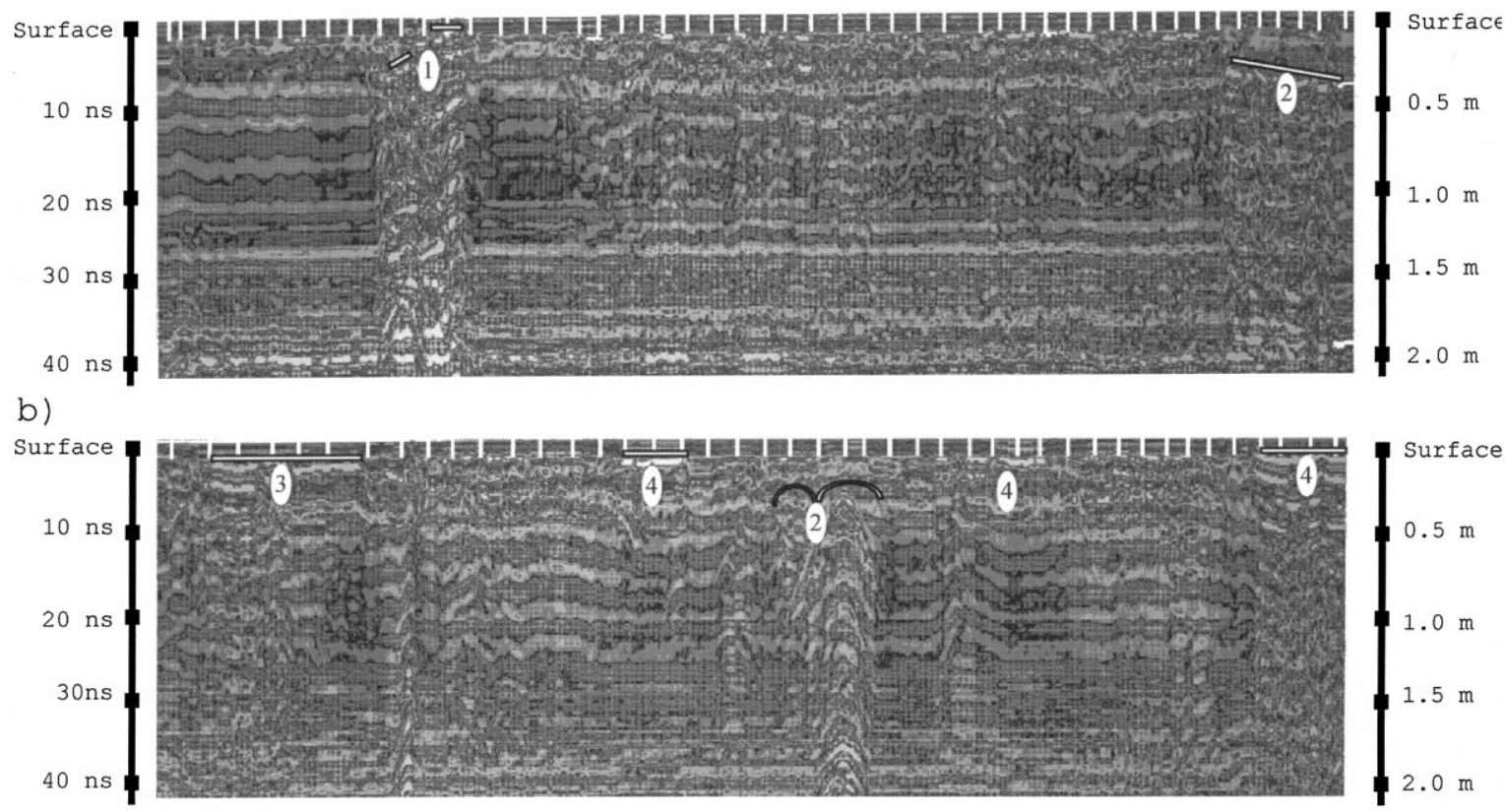

Fig. 2. (a) Radar data obtained along the central nave of the church (P1 profile). Surface distance: one tick correspond to 1 m. (b) Radar data obtained by crossing the central nave near the high altar (P5 profile). The most significant anomalies are indicated in the radar records: (1) Romanesque wall, (2) Crypt of "Capuchinos", (3) crypt and (4) grave.

(Carmichael, 1989; Sutinen, 1992; Lorenzo Cimadevila, 1994; Hänninen, 1997; Reynolds, 1997). This dielectric permittivity was used to convert the two-way travel time to depth in all profiles within the church. The presence of metal supports in the crypt roof may explain the multiple high-amplitude reflections observed in the radar records, because metal is a perfect radar

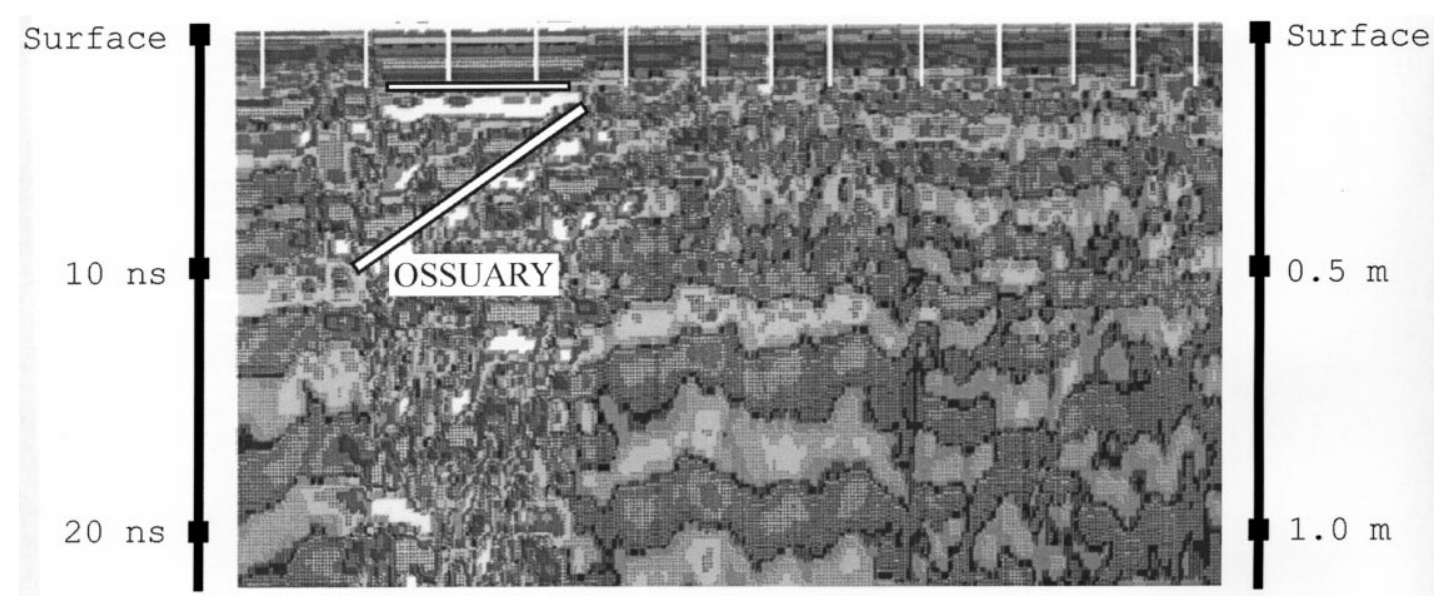

Fig. 3. Radar record obtained in a lateral chapel of the church, where a possible ossuary was detected (P8 profile). Distance: one tick corresponds to $1 \mathrm{~m}$. 
energy reflector. The GPR data in the P1 profile (Fig. 2a) show that the main cavity of this crypt is about $4 \mathrm{~m}$ wide. In addition, at the left side of profile P5, another crypt is detected in the lateral nave of the Cathedral.

Ossuaries are small cavities where the remains of corpses were relocated after being buried in graves for some time. These kind of burials are smaller than those in crypts, but usually they are placed deeper (Gavara, 1998, personal communication). Their exact location prior to the GPR surveys was unknown, but their existence was well-documented in archival records. In profile P1 (Fig. 2) the reflection anomalies produced by one possible ossuary are clearly shown. Radar reflections in Fig. 3 show a possible ossuary placed in a lateral chapel.

Graves were also detected during the survey in a number of profiles. Some of these graves are known because a tombstone or other marker was placed over them. In Fig. 4, the reflections from three of these graves are visible. Radar reflections also show lateral changes between floor tiling, the tombstones, and the reflections caused by the graves due to changes in construction material.

Radar profiles also allowed us to locate a number of undocumented graves by comparing reflection anomalies to known grave features. One of these is no more than $2 \mathrm{~m}$ long and
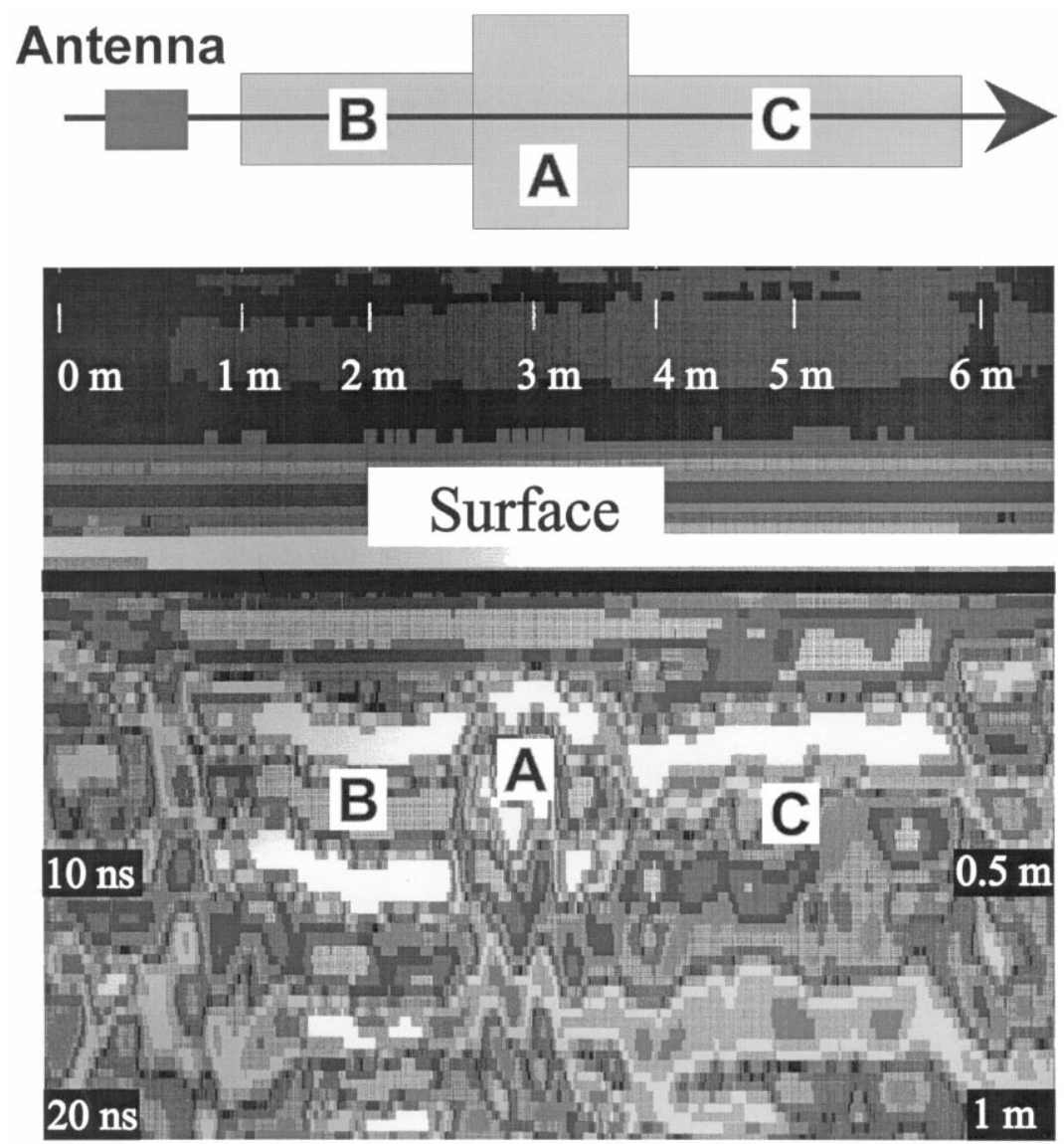

Fig. 4. (a) Scheme of the location of three known graves and the radar profile performed over them. (b) Section of the Radar record obtained in this profile ( $\mathrm{P} 3$ profile). The anomalies detected are: graves (A, B and C) and a tombstone between the surface and the grave. 


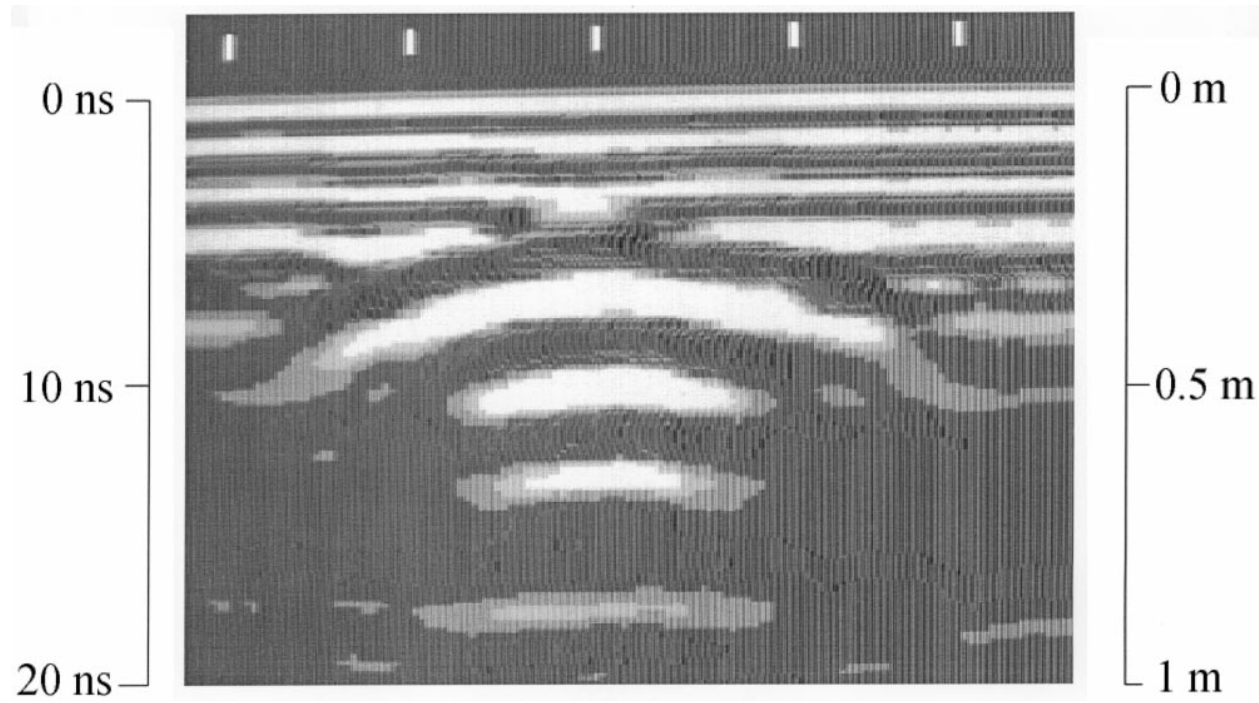

Fig. 5. Reflection produced by a grave under the floor of the church (P8 profile).

about a half-meter deep (Fig. 5). The high-amplitude reflection is caused by its shallow position and by the high reflection coefficient at the soil-to-air discontinuity. The reflection in Fig. 5 was recorded at 9 ns (two-way travel time). With an effective dielectric permittivity of 9 , the radar travel time can be estimated at approximately $10 \mathrm{~cm} / \mathrm{ns}$, indicating that the top of the grave is located about $45 \mathrm{~cm}$ under the floor tiling.

\section{Ancient constructive elements}

The location of an ancient Romanesque wall and the underlying construction layers were also investigated using GPR. During the last stage of the Cathedral construction (16th century), the building was expanded. At this time the Romanesque main wall (13th century) was demolished together with the houses of the canons, and a new wall was built in order to increase the size of the church. Although no documents indicate the location of this old wall, the time of the enlargement is well-documented. Using the GPR reflection data, probable positions of this wall and the small foundations of the houses were determined. In profiles P1 (along the main nave), P6, P7 (along the left nave), P8 and P9 (along the right nave), (Fig. 1) an anomalous reflector near the surface was found at the same distance from the existing main wall. The width of this anomaly ranges between 2.5 and $3 \mathrm{~m}$, corresponding to the dimensions of the partially demolished Romanesque wall.

Documentation, plans, and information about the location and use of the houses of the canons also exist in the archives, but other undocumented houses were also demolished during this same construction episode (Gavara, 1998, personal communication). The houses were probably small, private living quarters with thin walls and irregular construction located just outside the cathedral. Profile P2 (Fig. 6) was obtained in an area between the main wall of the present cathedral and the possible location of the demolished Romanesque wall. In Fig. 6, the possible remains of the demolished houses can be seen as irregular and low amplitude reflectors near the surface. The remains of the walls are no 


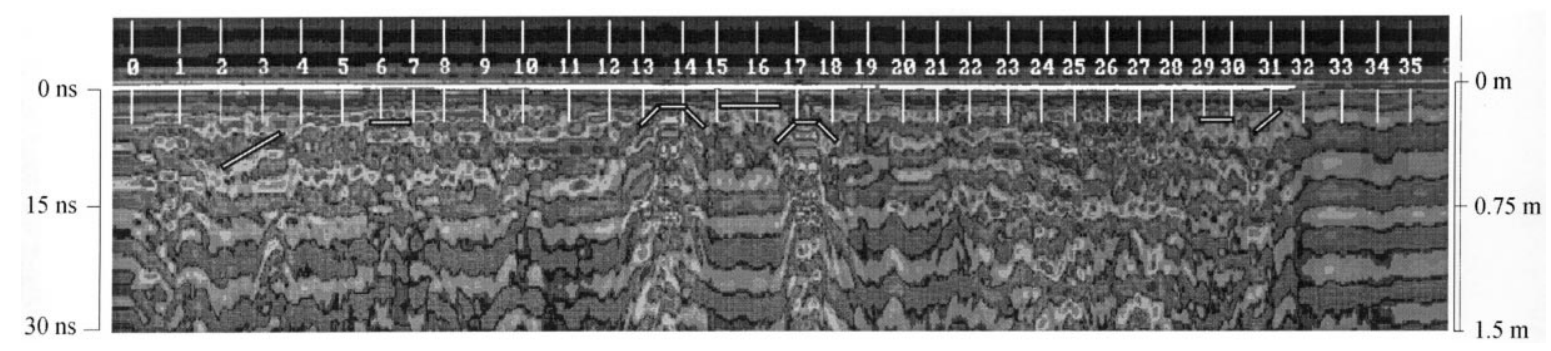

Fig. 6. Radar data obtained in the P2 profile. A number of shallow reflectors are detected along the 36-m profile. These reflection can be caused by the remains of 16th century houses demolished during the expansion of the Cathedral.

wider than $1 \mathrm{~m}$ and usually less than a half meter in width.

\section{Humidity damage}

Humidity is one of the main problems in the maintenance of the cathedral, probably caused by the shallow water table in this area. Some

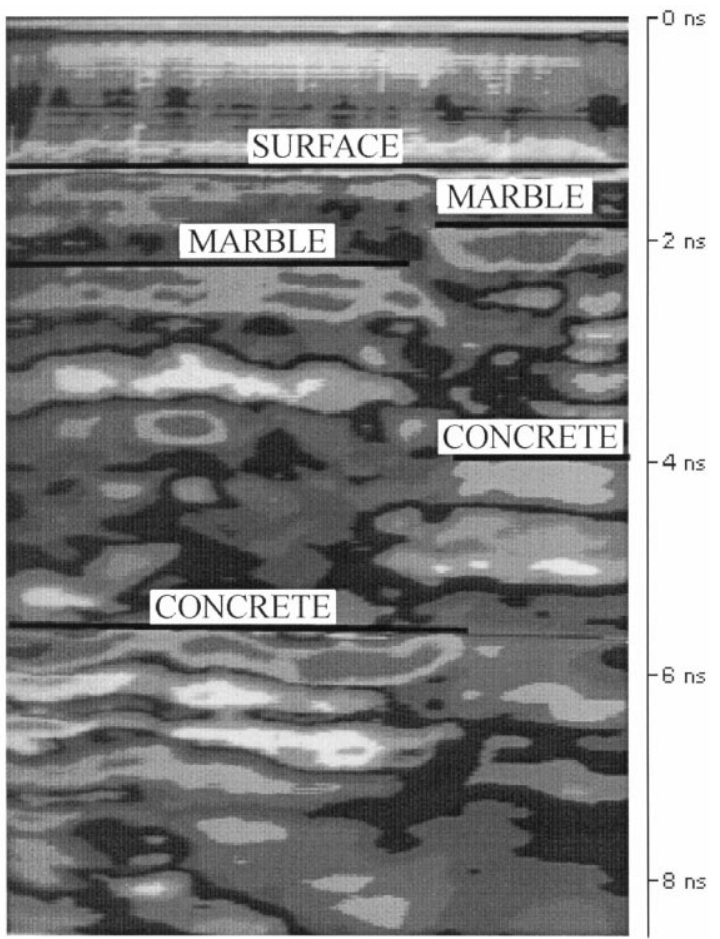

Fig. 7. Radar data obtained with a $900-\mathrm{MHz}$ center frequency antenna. Differences in the data of a humid area (left) and a non-humid area (right) are clearly seen. documents from the beginning of the 20th century (Gavara, 1997) report the existence of ground desiccation in the cathedral area, presumably due to shrinkage and expansion of clays within the nearby soils. The floor of the Cathedral is composed of marble slabs over the concrete, which is the most affected area of the church. Efflorescence due to salt precipitation can be observed as white spots on the black marble of the pavement caused by the upward translocation of ground water and its subsequent evaporation on the floor surfaces.

An area with abundant salt efflorescence was selected for GPR study. GPR reflection profiles in these areas were corrected to depth because the thickness of the floor was known in this area. Dielectric permittivity could then be calcu-

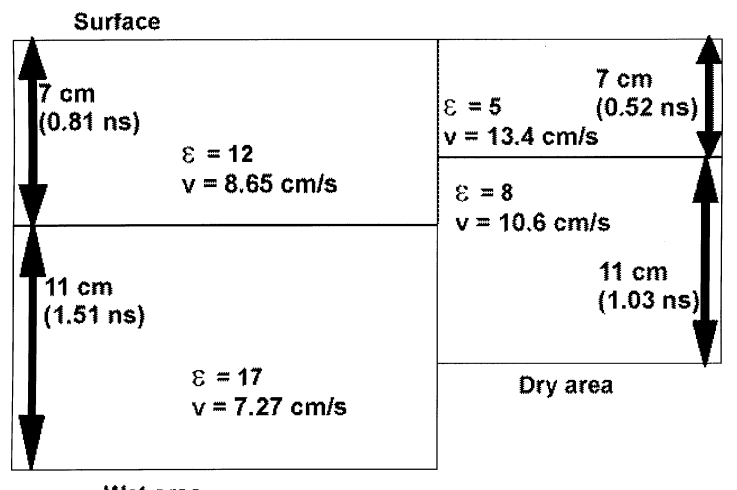

Wet area

Fig. 8. Scheme corresponding to the radar data of Fig. 7. The dielectric values in each area were obtained from the knowledge of the thickness of the slabs and the two-way travel time recorded. 
lated. Fig. 7 shows the reflection data in this area. Important differences between the propagating time in the humid and in the non-humid areas can be seen, which relate to differences in retained water.

In Fig. 8 the propagation velocities are shown. Significant differences are measurable between solid marble, concrete, the undamaged floor areas and the damp regions.

\section{Conclusions}

We obtained information about the existence of sub-floor remains without affecting the Valencia Cathedral. The GPR data allowed us to confirm some ancient maps and charts of the cathedral and also to locate different building episodes, only known from historical documentation. As a result of this study, we have been able to separate the subsurface features of the Cathedral in two main construction zones. In the Romanesque area, the reflection anomalies are caused by the differences in the constructive elements of the church. In the second area, outside the ancient Romanesque church, most of the anomalies are likely caused by the remains of small buildings that were located near outside walls of the Romanesque Cathedral. These constructions (private houses without monumental or social importance) are poorly documented in the Cathedral Archives.

Several other interesting features including graves and ossuaries were also detected under the floor of the Cathedral. Future archaeological excavations should investigate anomalies observed at $0.5 \mathrm{~m}$ depth in some of the radar profiles.

Finally, we were able to detect the three different construction layers. The Roman layer, probably the deepest anthropogenic horizon of the city, is located $2 \mathrm{~m}$ deep as shown in Figs. 2 and 3 . The shallower level $(0.5 \mathrm{~m})$ corresponds to construction from the 16th century to the present. The area between 1 and $1.5 \mathrm{~m}$ seems to correspond to the Middle Age and Visigothic occupation level.

The three main anthropogenic horizons of Valencia were detected. The anomalies located in these three levels show the three important constructive stages in this area of the Valencia City.

GPR was also used to detect humid areas and showed a clear difference between the humid and non-humid areas. Humidity problems are very common in old buildings, and it is convenient to perform a non-destructive survey with GPR prior to measures that can potentially repair and control them.

\section{Acknowledgements}

This study was supported in part by the CICYT (project number AMB98-0558) and the DGICYT of the Science and Culture Ministry (project number PB96-0139-C04-03); additional support was given by the Civil Engineering School (ETSECCPB) of the Politechnical University of Catalunya. Thanks are due to G.S. Baker and L.B. Conyers for their constructive reviews. J.J. Gavara provided us valuable information about the history of the Valencia City and its Cathedral. The help of Mr. J.J. Gavara and his group in the field surveys is also highly appreciated.

\section{References}

Carcione, J.M., 1996. Ground radar simulation for archaeological application. Geophysical Prospecting 44, 871888.

Carmichael, R.S., 1989. Physical Properties of Rocks and Minerals. CRC Press, USA, 741 pp.

Conyers, L.B., Goodman, D., 1997. Ground-Penetrating Radar: an Introduction for Archaeologists Walmunt Creek. Altamira Press, 20 pp.

Conyers, L.B., Jeffrey, E., Lucius, E., 1996. Velocity analysis in archaeological ground penetrating radar studies. Archaeological Prospection 3, 25-38.

Gavara, J.J., 1997. La Seu de la Ciutat. Catáleg de Plánols, 
Traces i Dibuixos de l'Arxiu de la Catedral de Valéncia (Fons Históric). Generalitat Valenciana, Valencia, España $367 \mathrm{pp}$.

Goodman, D., 1994. Ground-penetrating radar simulation in engineering and archaeology. Geophysics 59, 224232.

Hänninen, P., 1997. Dielectric coefficient surveying for overburden classification. Geological Survey of Finland, Bulletin 396, 72 pp.

Lorenzo Cimadevila, E., 1994. Prospección geofisica de alta resolucíon mediante geo-radar. Aplicación a obras civiles. Tesis doctoral. Universidad Complutense de Madrid, $201 \mathrm{pp}$.

Reynolds, J.M., 1997. An Introduction to Applied and Environmental Geophysics. Wiley (Eds.), England, 796 pp.

Sutinen, R., 1992. Glacial deposits, their electrical properties and surveying by image interpretation and ground penetrating radar. Geological Survey of Finland, Bulletin $359,123 \mathrm{pp}$. 